\title{
Ageing Indices and Energy Delivery for Polymers Undergoing PD Activity Under Combined AC and DC Stress
}

\author{
Weijia Zhao \\ Global Energy Interconnection Research Institute Co. Ltd, \\ State Key Laboratory of Advanced Power Transmission Technology, \\ Beijing 102211, China \\ Wah Hoon Siew and Martin J Given \\ University of Strathclyde \\ Department of Electronic \& Electrical Engineering \\ Glasgow G1 1XW, UK \\ Qingmin Li \\ North China Electric Power University \\ Beijing Key Laboratory of High Voltage \& EMC \\ Beijing, 102206, China \\ and Jinliang He \\ Tsinghua University \\ Department of Electrical Engineering \\ State Key Lab of Power Systems \\ Haidian, Beijing 100084, China
}

\begin{abstract}
Samples of Polypropylene and High Density Polyethylene have been exposed to partial discharge activity at elevated temperatures under the influence of combined $\mathrm{AC}$ and DC stresses in the range of 1 and $2.5 \mathrm{kHz}$. Based on FTIR-ATR and dielectric spectroscopy data values for the Carbonyl Index (CI), the low frequency conductivity $\left(\sigma_{0}\right)$ and a proposed new index the Susceptibility Index $(\chi \mathrm{I})$ have been calculated to characterize the degree of ageing in the samples. The Susceptibility Index reflects changes in the number of dipoles and the distribution of dipole moments in the system as a result of ageing. The rate of energy delivery from the partial discharge activity has also been calculated and has been found to be dependent on the frequency of the AC component of the stress. Strong correlations are observed between the behavior of the individual indices and the rate of energy delivery. Possible reasons for these observed correlations are discussed and the observed differences in the behavior of the ageing under different experimental conditions are considered.
\end{abstract}

Index Terms — partial discharge (PD), electrothermal aging, combined AC and DC aging, aging indices

\section{INTRODUCTION}

THE expected increases in the use of renewable energy sources such as photovoltaic cells and wind turbines has led to an increase in the requirements to transmit electrical power over long distances. This has led to an increase in the

Manuscript received on 5th Month 2018, in final form XX Month 20XX. importance of DC transmission systems due to their lower power losses and capital costs. [1,2]. The operation of power electronic convertors and invertors leads to the injection of relatively high frequency harmonics (of the order of $\mathrm{kHz}$ ) into the DC transmission system [3,4]. There are reports that the combination of $\mathrm{AC}$ and DC stresses on polymer insulated cables can lead to changes in the ageing and degradation of the insulating system. $[5,6]$.

Peer-reviewed, accepted author manuscript of the following research article: Zhao, W., Given, M., Siew, W. H., Li, Q., \& He, J. (Accepted/In press - 2019). Ageing Indices and Energy Delivery for Polymers Undergoing PD Activity Under Combined AC and DC Stress. IEEE Transactions on Dielectrics and Electrical Insulation, [8211]. 
It is therefore important that the influence of a combination of AC. and DC stresses on the ageing of polymer insulation is assessed, and that any changes in the underlying mechanisms are identified to permit realistic estimation of insulation lifetime under these conditions. In [7] the authors reported results from an investigation of the behavior of High Density Polyethylene (HDPE) samples subjected to partial discharge activity under combined AC and DC stressing. The test geometry was chosen to model the ring cutting and slitting defects that can occur at cable terminations [8]. The data in [7] reported the general behavior of the phase resolved PD activity and the measured changes in the FTIRATR and dielectric spectra for HDPE samples. This paper analyses both the data reported in [7] and additional data on the behavior of Polypropylene (PP) in more detail: quantifying the energy dissipated in the partial discharges and the ageing of the polymers in terms of the Carbonyl Index [9]; changes in the dielectric susceptibility and in the low frequency (DC) conductivity of the material. The behavior of the phase resolved partial discharge activity as a function of the combined $\mathrm{AC}$ and DC stresses in PP was similar to that reported in [7] and can be seen in [10]

\section{EXPERIMENTAL METHODS}

A full description of the experimental system is given in [7], so only the most significant details of the experimental system are described here.

\subsection{ELECTROTHERMAL AGEING SYSTEM}

The polymer materials, HDPE and PP were electrically stressed in a sphere plane gap at elevated temperatures in ambient air. The HDPE samples were tested at a temperature of $90^{\circ} \mathrm{C}$, which was just below the start of the melting peak for the material observed in Differential Scanning Calorimetry (DSC) thermograms. The PP samples were stressed at $90^{\circ} \mathrm{C}$ to provide commonality with the HDPE tests but were also stressed at $110^{\circ} \mathrm{C}$, again a temperature just below the start of the melting peak.

The polymers came in the form of $50 \mu \mathrm{m}$ films. It was found, [7] that a single thickness of film was subject to bulk breakdown under the conditions required for partial discharge initiation. Therefore two samples of area of $60 \times 60 \mathrm{~mm}^{2}$ were placed between the electrodes giving a total thickness of $100 \mu \mathrm{m}$. The upper, spherical, electrode was connected to a power amplifier with an output range of $50 \mathrm{kV}$ to $+50 \mathrm{kV}$. The lower electrode was connected to ground with a current transformer (HFCT, type KH-100M) to detect and quantify the PD activity. Only the sample, which was in contact with the sphere electrode and had been exposed to the PD activity, was subjected to post ageing analysis. Further information on the test system is available in [7] and on the polymers used in [10].

\subsection{AGEING CONDITIONS}

As the samples were subjected to a combination of AC and DC stresses, in [7] the authors specified the combined voltage waveform in terms of the frequency of the $\mathrm{AC}$ component and a Voltage Ratio $(A C \%)$ :
$A C \%=\frac{V_{A C}}{V_{D C}} .100$

where $\mathrm{V}_{\mathrm{AC}}$ is the peak value of the AC. component and $\mathrm{V}_{\mathrm{DC}}$ is the DC voltage value. The quality of power system voltages under AC conditions is often described by the Total Harmonic Distortion (THD). An equivalent to THD can be defined for a combined AC and DC waveform in terms of the ratio of the powers associated with the $\mathrm{AC}$ and $\mathrm{DC}$ components.

$T H D_{D C}=\frac{\left(V_{A C} / \sqrt{2}\right)^{2}}{V_{D C}}=\frac{1}{2}\left(\frac{V_{A C}}{V_{D C}}\right)^{2}$

In this work, the DC voltage was kept constant at $+6 \mathrm{kV}$ and the values of $A C \%$ used were: $10 \% ; 30 \%$ and $50 \%$. The equivalent levels of $T H D_{\mathrm{DC}}$ were: $0.005 ; 0.045$ and 0.125 respectively. Four frequencies for the AC component were used: $1 \mathrm{kHz} ; 1.5 \mathrm{kHz} ; 2 \mathrm{kHz}$ and $2.5 \mathrm{kHz}$.

The combination of AC and DC stressing resulted in surface discharge activity leading to the formation of a visibly degraded circular region centered on the point where the HV electrode was in contact with the surface. No measurable discharge activity occurred and no degradation was visible when the samples were exposed to pure DC stressing.

\subsection{DIAGNOSTIC EQUIPMENT}

During the ageing process, the PD activity occurring on the surface of the sample was measured using a current transformer with a bandwidth of $2 \mathrm{kHz}$ to $120 \mathrm{MHz}$ connected to a computer controlled oscilloscope with a bandwidth of $1.5 \mathrm{GHz}$ and a sampling rate of 10GS/s (Yokogawa DL6154). During the one-hour sample ageing period, the activity for two complete cycles of the AC waveform component were recorded every 2.4 seconds. This resulted in a total of 1500 cycle pairs. Once data acquisition had been completed, the PD signals associated with the first of each pair of cycles were de-noised in Matlab to produce phase resolved partial discharge data (PRPD).

Changes in the samples after ageing were assessed using FTIR-ATR and Dielectric Spectroscopy (DS) techniques. The FTIR-ATR spectra were measured in the range of $350 \mathrm{~cm}^{-}$ 1 to $4000 \mathrm{~cm}^{-1}$ using a Thermos Fisher Nicolet iS 16 spectrometer. These measurements were performed on six equally spaced regions of each sample at a radial distance of $1 \mathrm{~mm}$ from the point of contact with the HV electrode, the center of the aged area. Dielectric Spectra were measured on samples with a diameter of $20 \mathrm{~mm}$ again centered on the point of contact between the HV electrode and the polymer, using a Novocontrol Concept 82 spectroscopy system in the range of $10^{-2}$ to $10^{4} \mathrm{~Hz}$.

\section{AGEING PARAMETERS}

\subsection{CUMULATIVE APPARENT ENERGY AND ITS RATE OF DELIVERY}

To characterize the energy input into the system as a result of $\mathrm{PD}$ activity, the measured $\mathrm{PD}$ voltage amplitudes were used to calculate an approximation, proportional to the total energy delivered. 
For each PD pulse, the actual PD energy $E$ could be calculated from a measured voltage transient $v_{\text {Meas }}(t)$ using: $E=\frac{R_{D}}{g} \int_{0}^{T} v_{\text {meas }}(t) d t$

Where $R_{D}$ is the resistance of the discharge channel, assumed constant over the period of the discharge, $g$ is transresistance gain of the current transformer and $T$ is the pulse duration.

The total PD energy recorded during aging, $E_{C R}$, will be a summation of energy of each PD pulse recorded.

$$
E_{C R}=\frac{R_{D E}}{g} \sum_{k=1}^{n} \int_{0}^{T} v_{\text {meas }}(t) d t
$$

where $n$ is the number of pulses recorded and it is assumed that a single effective discharge channel resistance $R_{D E}$ can be used for all PD events.

If the shape of the individual PD pulses are broadly similar, then the integral term in the summation in (4) can be approximated by:

$$
\int_{0}^{T} v_{\text {Meas }}^{2}(t) d t=\beta T_{k} v_{k}^{2}
$$

where $\beta$ is a constant parameter depending on the assumed common shape of the partial discharges and $v_{k}$ and $T_{k}$ are the peak voltage and duration associated with the discharge event. If a final assumption is made that the period of the individual PD events can be approximated by a common effective period $T_{E}$, Equation (4) can be rewritten as:

$$
E_{C R}=\frac{R_{D E}}{g} \beta T_{E} \sum_{k=1}^{n} v_{k}^{2}
$$

As the term $g$ is constant and the terms $R_{D E}, \beta$ and $T_{E}$ are assumed to be constant, the final summation term in (6) should be proportional to the cumulative energy and is referred to as the apparent cumulative energy $E_{C A}$.

$E_{C A}=\sum_{k=1}^{n} v_{k}^{2}$

The data on partial discharge activity used by the authors came from 1500 cycles of the AC component of the voltage stress. The values of $\mathrm{E}_{\mathrm{CA}}$ calculated for different frequencies are therefore based on different total periods of measurement $T_{M}$. Hence, the rate of apparent energy delivery $P_{C A}$ is a more useful index for comparison

$$
P_{C A}=\frac{E_{C A}}{T_{M}}=\frac{f}{1500} E_{C A}
$$

\subsection{CARBONYL INDEX}

When polyolefin samples are aged, chain scission occurs and subsequent reactions lead to the formation of hydroxyl groups $(\mathrm{O}-\mathrm{H})$ and carbonyl groups $(\mathrm{C}=\mathrm{O})[11,12]$. This leads to increases in absorption in FTIR-ATR spectra in the region between $3500 \mathrm{~cm}^{-1}$ to $3000 \mathrm{~cm}^{-1}$ for $(\mathrm{O}-\mathrm{H})$ groups and between $1750 \mathrm{~cm}^{-1}$ to $1600 \mathrm{~cm}^{-1}$ for $(\mathrm{C}=\mathrm{O})$ groups. Peaks associated with the methylene group in the range of $2800 \mathrm{~cm}^{-}$ ${ }^{1}$ to $1600 \mathrm{~cm}^{-1}$ and $1350 \mathrm{~cm}^{-1}$ to $1480 \mathrm{~cm}^{-1}$ will decrease as a result of these reactions. The Carbonyl Index (CI) attempts to quantify the degree of ageing by looking at the ratio of carbonyl absorbance to methylene absorbance. [11,12] define the Carbonyl Index in terms of the carbonyl $A_{1720}$ and the methylene $A_{1463}$ absorptions.

$C I=\frac{A_{1720}}{A_{1463}}$

This approach allows the ageing of a sample of polymer material to be in part quantified. However, while it is possible to use the CI calculated using Equation (9) to compare the degree of ageing of samples of a single polymer, it is not possible to directly compare the CI values of differing polymers.

\subsection{LOW FREQUENCY OR DC CONDUCTIVITY}

As reported in $[7,10]$ at frequencies below $1 \mathrm{~Hz}$ a rise in $\tan \delta$ was observed as the frequency decreased for aged sample of HDPE, while the value of $\varepsilon^{\prime}$ though dependent on the ageing conditions, was constant. This behavior can be attributed to DC conduction processes [13]. Under all ageing conditions the plots of $\varepsilon^{\prime \prime}$ against $1 / \omega$ were linear in the low frequency range allowing values of the dc conductivity $\sigma_{0}$ to be obtained.

\subsection{PERMITTIVITY AND SUSCEPTIBILITY INDEX}

In $[7,10]$ the real part of the relative permittivity was observed to increase as a function of ageing. As a way of quantifying such changes, the authors have defined a Susceptibility Index $(\chi I)$ :

$\chi I=\frac{\chi_{A}-\chi_{U}}{\chi_{U}}$

Where $\chi_{U}$ is the value of the dielectric susceptibility measured for an unaged sample and $\chi_{A}$ is that measured for a particular ageing condition. Dielectric susceptibility quantifies the relationship between the polarization density $\mathbf{P}$ and the electric field vector $\mathbf{E}$ in a material. $\mathbf{P}$ and therefore the value of $\chi$ will depend on the population, in terms of the type and number per unit volume, of dipoles in a sample and the dipole moment for each type of dipole. During ageing dipoles with a low moment such as methyl groups are replaced with dipoles with a higher dipole moment such as carbonyl groups. This index therefore represents the change in the polarization density due to the change in the dipole distribution due to ageing, normalized by the original polarization density.

\section{DERIVED PARAMETER VALUES}

Based on the partial discharge data, values for the apparent power delivery $P_{C A}$ were calculated. The dielectric spectra were used to calculate values for the conductivity $\sigma_{0}$ and the susceptibility index $\chi I$. The FTIR ATR spectra were used to calculate values for the carbonyl index CI.

\subsection{RATE OF APPARENT ENERGY DELIVERY}

The derived values of $P_{C A}$ at $\mathrm{AC} \%{ }_{030}$ and $\mathrm{AC} \%{ }_{50}$ for $\mathrm{HDPE}$ stressed at $90^{\circ} \mathrm{C}$ are shown in Figure 1 . The calculated values of $P_{C A}$ increase in a close to linear manner with the frequency of the AC component of the applied waveform. This was also observed in the PP samples. The gradients of linear fits to the $P_{C A}$ values as a function of frequency are given in Table 1. These fits assumed that the value of $P_{C A}$ was zero under DC 
conditions. The values of $P_{C A}$ are significantly higher for the $\mathrm{AC} \%{ }_{50}$ tests as compared to the $\mathrm{AC} \%{ }_{30}$ tests. This reflects the differences in the partial discharge activity reported in [7]. For the samples stressed at $\mathrm{AC} \% 10$ the values of $P_{C A}$ are again lower. As there were little or no change in the values of $\sigma_{0}, \chi \mathrm{I}$ and CI for this voltage ratio these results are not presented in this paper.

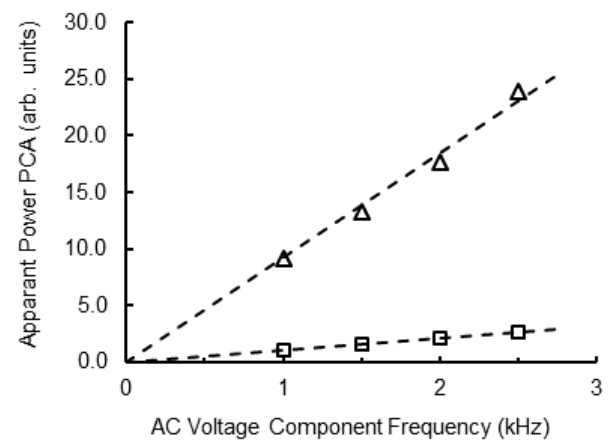

Figure 1 (a). Rate of apparent energy delivery vs. frequency of AC component for HDPE aged at $90^{\circ} \mathrm{C}: \square 30 \%$ voltage ratio, $\Delta 50 \%$ voltage ratio.

Table 1. Mean of recorded PD voltages and their standard deviation for PP samples aged at $110^{\circ} \mathrm{C}[10]$

\begin{tabular}{c|c|c|c}
\hline Material, Temperature & $\mathrm{AC} \%$ & Gradient $\left(P_{C A} / \mathrm{kHz}\right)$ & $\mathrm{R}^{2}$ \\
\hline \multirow{2}{*}{$\mathrm{HDPE}, 90^{\circ} \mathrm{C}$} & $30 \%$ & $1.08 \pm 0.01$ & 1.00 \\
& $50 \%$ & $9.20 \pm 0.2$ & 0.999 \\
\hline \multirow{2}{*}{$\mathrm{PP}, 90^{\circ} \mathrm{C}$} & $30 \%$ & $0.84 \pm 0.01$ & 1.00 \\
& $50 \%$ & $7.29 \pm 0.21$ & 0.998 \\
\hline \multirow{2}{*}{$\mathrm{PP}, 110^{\circ} \mathrm{C}$} & $30 \%$ & $1.37 \pm 0.08$ & 0.991 \\
& $50 \%$ & $10.8 \pm 0.32$ & 0.997 \\
\hline
\end{tabular}

\subsection{CARBONYL INDEX}

The behavior of the calculated values of $\mathrm{CI}$ as the frequency of the AC component was varied are shown in Figure 2 . The $A_{1720}$ peak was not present in unaged HDPE and PP samples or in samples exposed to only a DC stress, therefore $\mathrm{CI}$ had a value of zero for these conditions. For the HDPE sample at $90^{\circ} \mathrm{C}$ and the PP sample at both 90 and $110^{\circ} \mathrm{C}$ for $\mathrm{AC} \%{ }_{030}$ stressing, $\mathrm{CI}$ appears to increase in a linearly with the frequency of the AC component.

The values calculated for CI are larger for the PP samples but as mentioned above, direct comparisons of the CI values calculated for different materials are not valid.

. The values of $\mathrm{CI}$ in each experimental condition are higher for $\mathrm{AC} \%{ }_{50}$ than for $\mathrm{AC} \% 30$ and again the value of the $\mathrm{CI}$ increases with the frequency of the $\mathrm{AC}$ component. For HDPE samples aged at $90^{\circ} \mathrm{C}$ and $\mathrm{PP}$ samples aged at $110^{\circ} \mathrm{C}$ some saturation of the value of CI can be observed at higher frequencies. Possible explanations for this behavior are discussed in section 5.4

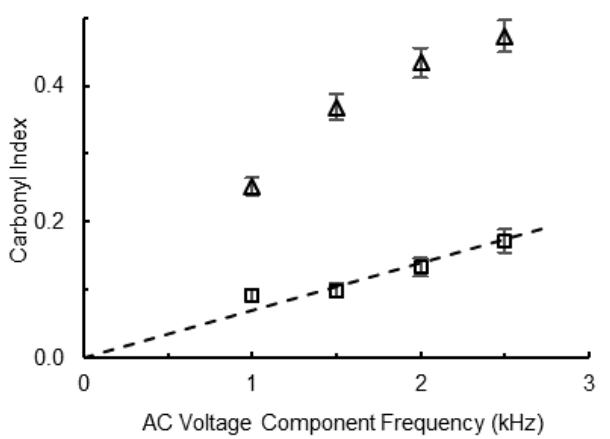

Figure 2(a). Carbonyl Index vs. frequency of AC component for HDPE aged at $90^{\circ} \mathrm{C}$ : $\square 30 \%$ voltage ratio, $\Delta 50 \%$ voltage ratio.

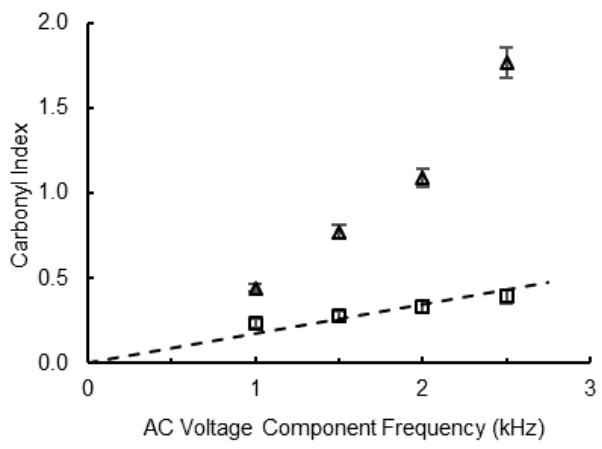

Figure 2(b). Carbonyl Index vs. frequency of AC component for PP aged at $90^{\circ} \mathrm{C}: \square 30 \%$ voltage ratio, $\Delta 50 \%$ voltage ratio.

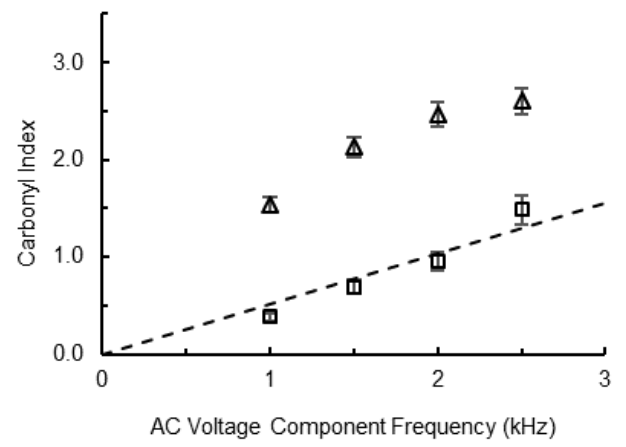

Figure 2(c). Carbonyl Index vs. frequency of AC component for PP aged at $110^{\circ} \mathrm{C}$ : $\square 30 \%$ voltage ratio, $\Delta 50 \%$ voltage ratio.

\subsection{LOW FREQUENCY CONDUCTIVITY $\sigma_{0}$.}

For unaged samples the value of $\sigma_{0}$ was $1.37 \pm 0.14 \times 10^{-16}$ $\mathrm{S} / \mathrm{m}$ for HDPE and $2.06 \pm 0.19 \times 10^{-16} \mathrm{~S} / \mathrm{m}$ for PP.

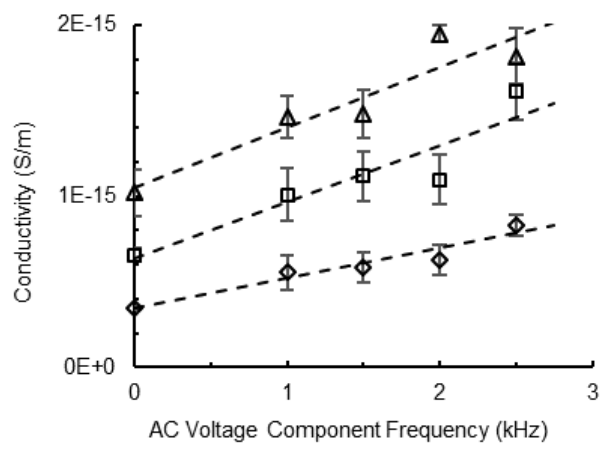

Figure 3(a). Conductivity vs. frequency of $\mathrm{AC}$ component using $30 \%$ voltage ratio: $\square \mathrm{HDPE}$ at $90^{\circ} \mathrm{C}, \diamond \mathrm{PP}$ at $90^{\circ} \mathrm{C}, \Delta \mathrm{PP}$ at $110^{\circ} \mathrm{C}$ 


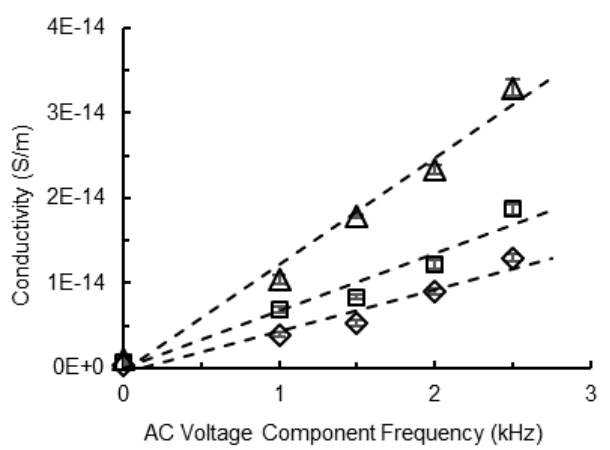

Figure 3(b). Conductivity vs. frequency of AC component using $50 \%$ voltage ratio: $\square \mathrm{HDPE}$ at $90^{\circ} \mathrm{C}, \diamond \mathrm{PP}$ at $90^{\circ} \mathrm{C}, \Delta \mathrm{PP}$ at $110^{\circ} \mathrm{C}$

Figure $3 \mathrm{a}$ shows the behavior of $\sigma_{0}$ as a function of the frequency of the AC component for HDPE and PP samples

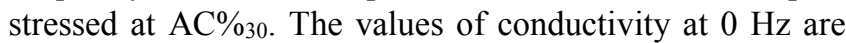
those obtained from samples stressed only with DC voltage. It can be seen that $\sigma_{0}$ increases with the frequency of the $\mathrm{AC}$ component. The derived values of $\sigma_{0}$ for PP aged at $110^{\circ} \mathrm{C}$ are greater for those for $\mathrm{PP}$ aged at $90^{\circ} \mathrm{C}$.

For the samples aged at $\mathrm{AC} \% 50$, Figure $3 \mathrm{~b}$, the values of $\sigma_{0}$ derived are significantly higher in each case than those for $\mathrm{AC} \%$ 30. The relationship between $\sigma_{0}$ and the frequency of the applied AC component is linear.

Again the values of $\sigma_{0}$ for PP samples aged at $110^{\circ} \mathrm{C}$ are higher than those aged at $90^{\circ} \mathrm{C}$.

\subsection{SUSCEPTABILITY INDEX $\chi$ I}

For all experimental conditions no significant structures were observed in the $\varepsilon^{\prime}$ spectra in the range of $10^{1}$ to $10^{4} \mathrm{~Hz}$. Therefore, an average value over this range was used to calculate the value of the susceptibility. From the definition of the susceptibility index (10), the value of $\chi I$ for unaged samples will be zero. The behavior of the susceptibility index as a function of the frequency of the $\mathrm{AC}$ component for the various ageing conditions for the HDPE and PP material are shown in Figure 4. The values of $\chi I$ at $0 \mathrm{~Hz}$ were based on the derived values of $\chi$ for samples aged in the absence of an $\mathrm{AC}$ voltage component. In Figure 4 for both the HDPE and the PP samples the susceptibility index increases with the frequency of the $\mathrm{AC}$ voltage component in a linear manner.

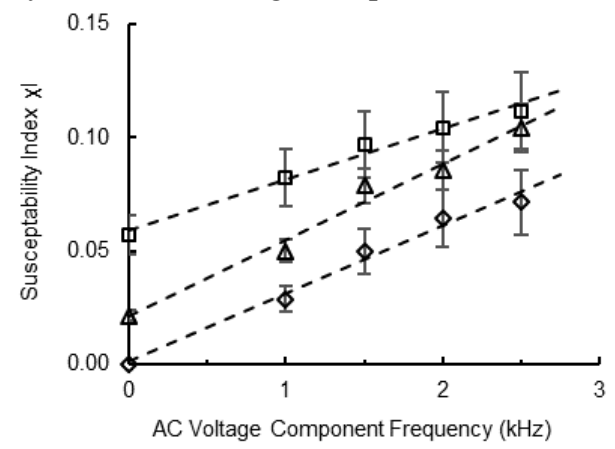

Figure 4(a). Susceptibility Index $\chi \mathrm{I}$ vs. frequency of $\mathrm{AC}$ component using $30 \%$ voltage ratio: $\square \mathrm{HDPE}$ at $90^{\circ} \mathrm{C}, \diamond \mathrm{PP}$ at $90^{\circ} \mathrm{C}, \Delta \mathrm{PP}$ at $110^{\circ} \mathrm{C}$.

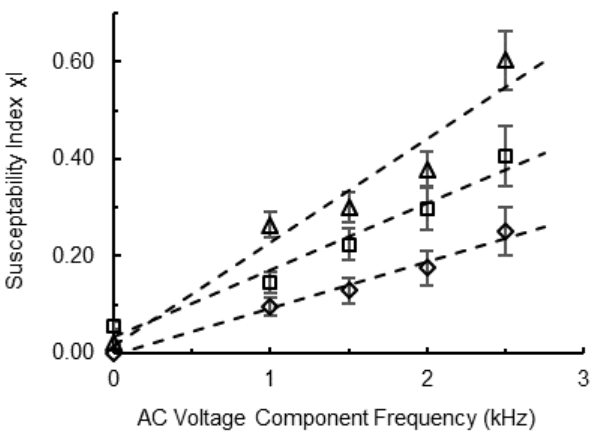

Figure 4(b). Susceptibility Index $\chi \mathrm{I}$ vs. frequency of $\mathrm{AC}$ component using $50 \%$ voltage ratio: $\square \mathrm{HDPE}$ at $90^{\circ} \mathrm{C}, \diamond \mathrm{PP}$ at $90^{\circ} \mathrm{C}, \Delta \mathrm{PP}$ at $110^{\circ} \mathrm{C}$.

The changes in the $\chi I$ for samples which were aged at $\mathrm{AC} \%{ }_{50}$ are larger than those for samples aged at $\mathrm{AC} \%{ }_{30}$. For the PP samples, the changes in $\chi I$ are larger for the samples aged at $110^{\circ} \mathrm{C}$ as compared to those aged at $90^{\circ} \mathrm{C}$.

\section{COMPARISON OF INDEX BEHAVIOURS AND DISCUSSION}

\subsection{COMPARISONS BETWEEN AGING INDICES бo AND $\chi 1$}

Figure 5a shows a plot of $\sigma_{0}$ vs $\chi I$ for the HDPE samples aged at $90^{\circ}$ at $\mathrm{AC} \% 0_{30}$ and $\mathrm{AC} \%$. The values for $\mathrm{AC} \%{ }_{50}$ appears to fall close to a linear trend. $\left(\mathrm{R}^{2}=0.979\right)$. The points associated with the $\mathrm{AC} \%$ data fall significantly below the trend-line for the $\mathrm{AC} \% 5_{0}$ data

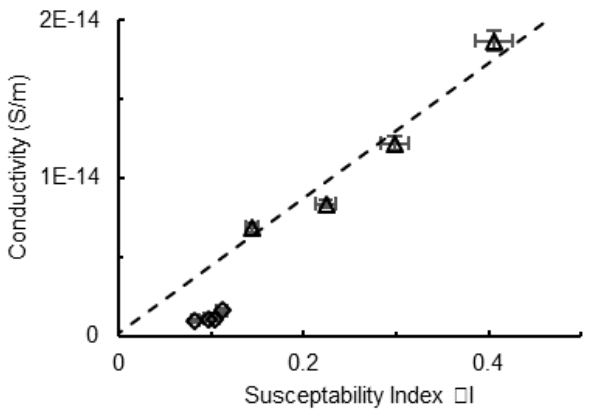

Figure 5(a). Conductivity vs. Susceptibility Index $\chi \mathrm{I}$ for HDPE at $90^{\circ} \mathrm{C}: \diamond 30 \%$ voltage ratio; $\Delta 50 \%$ voltage ratio

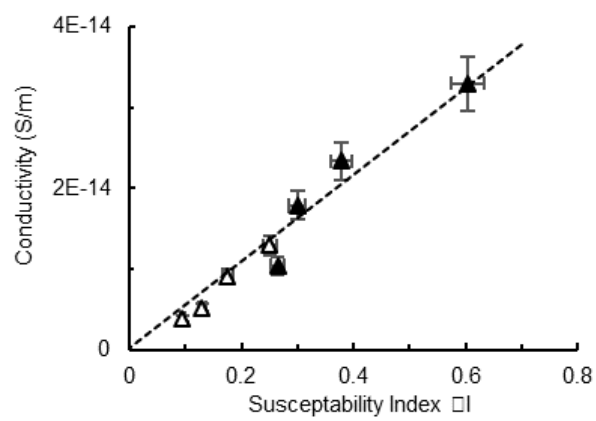

Figure 5(b). Conductivity vs. Susceptibility Index $\chi \mathrm{I}$ for PP aged at $50 \%$ voltage ratio open symbols $90^{\circ} \mathrm{C}$, closed symbols $110^{\circ} \mathrm{C}$

Figure $5 \mathrm{~b}$ shows the data for the PP samples aged at $\mathrm{AC} \% 50$ voltage ratio at both $90^{\circ}$ and $110^{\circ} \mathrm{C}$. The data from both ageing temperatures shows a linear correlation between $\sigma_{0}$ 
and $\chi I\left(\mathrm{R}^{2}=0.981\right)$.As with HDPE the data for $\mathrm{AC} \% 30$ for both temperatures lies considerably below the trend associated with the $\mathrm{AC} \%{ }_{50}$ data and has been omitted from Figure $5 \mathrm{~b}$ for clarity. This behavior suggests that are significant differences for both polymers, between the ageing processes that occurs at $\mathrm{AC} \% 50$ and $\mathrm{AC} \% 30$, with the latter resulting in a much smaller change in the low frequency conductivity as compared with the changes in susceptibility index.

\subsection{COMPARISONS BETWEEN $\chi \mathrm{I}, \sigma_{0}$ INDICES AND Cl}

As there are linear relationships between the DC conductivity $\sigma_{0}$ and the susceptibility index $\chi \mathrm{I}$ at $\mathrm{AC} \%{ }_{50}$ comparisons will only be made between the Susceptibility Index and Carbonyl Index. in this section as no significant additional information is obtained by comparisons with the DC conductivity. It can be seen in Figure 6 that the relationship between $\mathrm{CI}$ and $\chi I$ is non- linear and empirical trendlines of the form:

$$
C I(\chi I)=A\left(1-\exp \left(-B\left(\chi I-\chi I_{d c}\right)\right)\right)
$$

have been fitted to the data as this provides the simplest analytical form for a saturation behavior. $\chi I_{d c}$ is the value of the susceptibility index for samples that were aged under only DC stress. For HDPE the data for both $\mathrm{AC} \% 30$ and $\mathrm{AC} \% 50 \%$ falls close to a common exponential trend line. For PP the data for $\mathrm{AC} \% 50$ at both 90 and $110^{\circ} \mathrm{C}$ falls close to a single trend line.

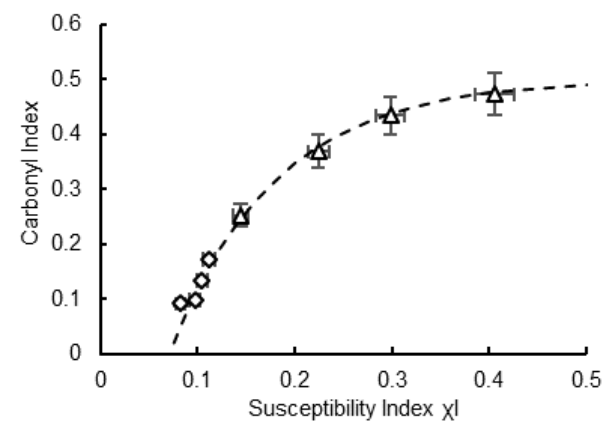

Figure 6(a). Carbonyl Index vs. Susceptibility Index for HDPE at $90^{\circ} \mathrm{C}: \diamond 30 \%$ voltage ratio; $\Delta 50 \%$ voltage ratio.

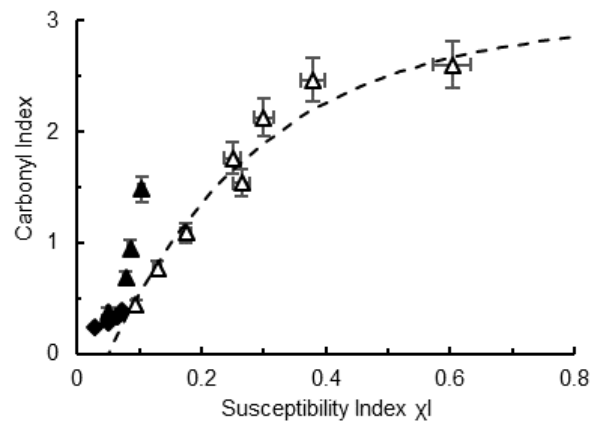

Figure 6(b). Carbonyl Index vs. Susceptibility Index for PP: open symbols aged at $50 \%$, closed symbols aged at $30 \%$ voltage ratio open symbols $90^{\circ} \mathrm{C}$, closed symbols $110^{\circ} \mathrm{C} . \diamond 90^{\circ} \mathrm{C} ; \Delta 100^{\circ} \mathrm{C}$.

Though it should be noted from Figure $4 \mathrm{~b}$ that the value of $\chi I_{d c}$ is different for the two ageing temperatures. The data for $\mathrm{PP}$ aged at $\mathrm{AC} \%{ }_{30}$ falls distinctly above this trend line, suggesting that under these conditions the Carbonyl Index increases more rapidly compared to the Susceptibility index.

\subsection{RELATIONSHIP BETWEEN AGING INDICES AND APPARENT POWER}

Based on Equations (3) to (8) estimates were made of the rate at which energy was being dissipated in the partial discharge activity during ageing for the various stressing conditions considered. Figure 7 shows the relationship of $\chi \mathrm{I}$ relating to changes in the polymer due to aging and $P_{C A}$ which relates to the total energy supplied to the system during aging. In Figure $7 \mathrm{a}$ it can be seen that the data points for $\mathrm{HDPE}$ aged at $90^{\circ} \mathrm{C}$ for both $\mathrm{AC} \% 30$ and $\mathrm{AC} \% 50$ have a common linear behavior with respect to $P_{C A}\left(\mathrm{R}^{2}=0.971\right)$. For the PP data shown in Figure 7(b) for the samples aged at $110^{\circ} \mathrm{C}$ there is again a common linear behavior for both $\mathrm{AC} \%{ }_{30}$ and $\mathrm{AC} \%{ }_{50}\left(\mathrm{R}^{2}=0.975\right)$. For the PP samples aged at $90^{\circ} \mathrm{C}$ the data obtained at $\mathrm{AC} \%$ follows a linear trend $\left(\mathrm{R}^{2}=\right.$ 0.945). The data at $\mathrm{AC} \%{ }_{30}$ however falls above this trend line. It is not shown in Figure $7 \mathrm{~b}$ as it is superimposed on the $\mathrm{AC} \%{ }_{30}$ data for $110^{\circ} \mathrm{C}$. As would be expected due to the strong linear correlation between $\sigma_{0}$ and the $\chi I$ similar behaviors exist in the relationship between $\sigma_{0}$ and $P_{C A}$ at $\mathrm{AC} \% 50$.

The relationships between the derived Carbonyl Index and the apparent power delivered to the discharges for HDPE aged at $90{ }^{\circ} \mathrm{C}$ are shown in Figure 8a The AC\%50 data is nonlinear with the rate of increase in Carbonyl Index decreasing as the apparent power delivery increases. The data can be fitted to an exponential function of the form of Equation (11). The data for HDPE aged at $\mathrm{AC} \%{ }_{30}$ falls above this line of fit

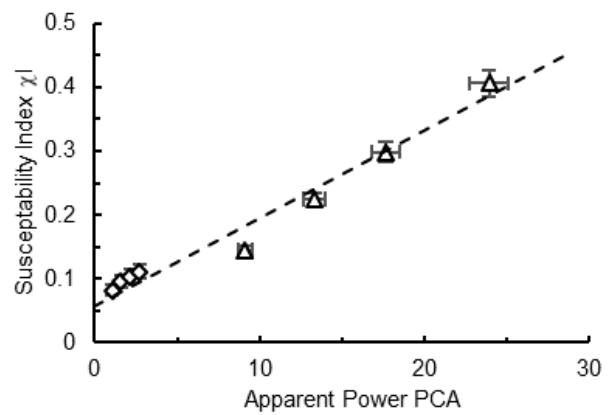

Figure 7(a). Susceptibility Index vs $P_{C A}$ for HDPE at $90^{\circ} \mathrm{C}: \diamond 30 \%$ voltage ratio; $\Delta 50 \%$ voltage ratio.

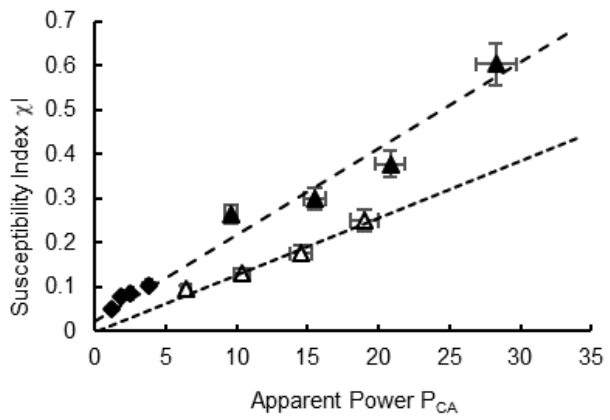

Figure 7(b). Susceptibility Index vs $P_{C A}$ for PP $\diamond 30 \%$ voltage ratio; $\Delta$ $50 \%$ voltage ratio. Open Symbols aged at $90^{\circ} \mathrm{C}$, closed Symbols aged at $110^{\circ} \mathrm{C}$ 
. A similar behavior is seen for the PP data in Figure $8 \mathrm{~b}$. The $\mathrm{AC} \% 50$ data at $110^{\circ} \mathrm{C}$ can again be fitted to (11). A fit to this function for $\mathrm{AC} \% 50$ data at $90^{\circ} \mathrm{C}$ is also possible but the fit is less good. For both the $90^{\circ}$ and $110^{\circ} \mathrm{C}$ the $\mathrm{AC} \%{ }_{30}$ data falls above the fit lines for the corresponding $\mathrm{AC} \%{ }_{50}$ data.

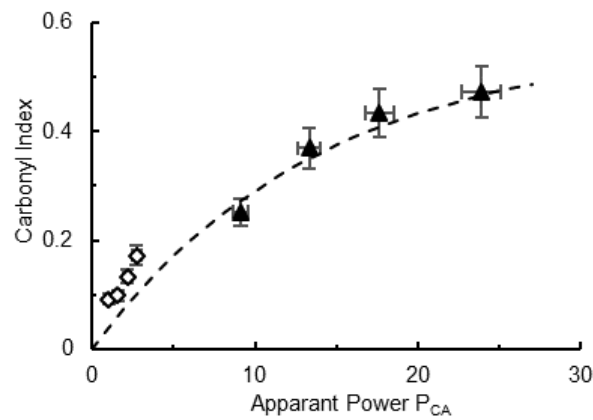

Figure 8(a) Carbonyl Index vs. apparent power for HDPE aged at $90^{\circ} \mathrm{C}$ : $\diamond 30 \%$ voltage ratio, $\Delta 50 \%$ voltage ratio.

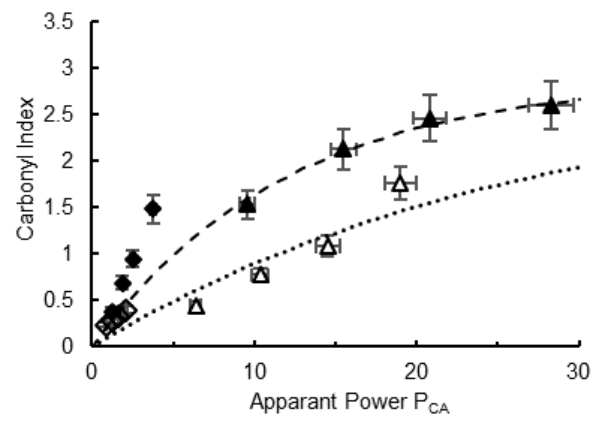

Figure 8(b) Carbonyl Index vs. apparent power for PP: $\diamond 30 \%$ voltage ratio, $\Delta 50 \%$ voltage ratio; Open symbols aged at $90^{\circ} \mathrm{C}$, closed symbols aged at $110^{\circ} \mathrm{C}$.

\subsection{DISCUSSION}

From the data it is not possible to separate the effects of thermal ageing and the effects of pure DC stressing. No partial discharge activity was observed in the DC stressed samples, so any changes are expected to be due to thermal ageing. Pure DC stress does not lead to changes in the Carbonyl Index. For HDPE the value of $\sigma_{0}$ increased from $1.37 \pm 0.14 \times 10^{-16} \mathrm{~S} / \mathrm{m}$ to $6.57 \pm 0.07 \times 10^{-16} \mathrm{~S} / \mathrm{m}$. For PP the values of $\sigma_{0}$ increased from $2.06 \pm 0.18 \times 10^{-16} \mathrm{~S} / \mathrm{m}$ to $3.47 \pm$ $0.88 \times 10^{-16} \mathrm{~S} / \mathrm{m}$ at $90^{\circ} \mathrm{C}$ and to $10.3 \pm 0.02 \times 10^{-16} \mathrm{~S} / \mathrm{m}$ at $110^{\circ} \mathrm{C}$. The values of $\chi I$ has a value of 0.07 for the HDPE exposed to DC stress at a temperature of $90^{\circ} \mathrm{C}$. For PP it is 0 for DC stress at $90^{\circ} \mathrm{C}$ but increases to 0.07 at $110^{\circ} \mathrm{C}$. Looking at the data for combined $\mathrm{DC}$ and $\mathrm{AC}$ stressing at a frequency of $2.5 \mathrm{kHz}$ under $\mathrm{AC} \% 30$ conditions the additional change in $\sigma_{0}$ and are $\chi I$ of the same order of magnitude as any effect of thermal and DC aging. Under AC\%50 conditions the changes observed as a result of stressing are much more significant than the effect of combined DC and thermal stress.

For samples aged at $\mathrm{AC} \% 50$ there are strong linear correlations between $\sigma_{0}$ and $\chi I$. There are also linear correlations between these indices and the rate of apparent energy delivery to the system $P_{C A}$. The discharge activity onto and across the surface of the polymer provides energy to the system in the form of electrons, ions, active species and high- energy (UV) photons. This results in changes in the morphology and structure of the polymer, which can lead to the formation of new trapping sites or the reduction in the depth of the traps already present in the system [14-16]. This would lead to increases in $\sigma_{0}$ : firstly through the increase in the number of charge carriers within the system due to the increase in the available trapping sites and secondly through the higher average mobility of the charge carriers due to reductions in the average trap depth. Oxidative reactions are also taking place in the polymer due to the partial discharge activity [17-19] leading to the presence of more polar groups such as the carbonyl group in the polymer increasing its polarizability and therefore leading to an increase in the values of the susceptibility index. These oxidative processes will also result in significant changes in the IR spectra. [7, 10] as have been quantified through the Carbonyl Index.

If it is assumed that, at a constant temperature, the rate at which these modifications to the polymer morphology, structure and chemical composition will occur depends on the rate of energy delivery to the surface from the discharge activity. This assumption implies that over the period of the ageing process the concentration of unreacted/unaged polymer remains near constant. The rate of energy delivery will increase as the power supplied by the discharge activity increases leading to a corresponding increase in the aging of the polymer. This would result in the observed correlations between $\sigma_{0}$ and $\chi I$ with $P_{C A}$.

The nonlinear behavior of the CI data when compared to the behavior of $\sigma_{0}$ and $\chi I$ may result from the limited penetration depth of the evanescent wave employed by FTIR ATR spectroscopy at the point of total reflection. The amplitude of this wave decays exponentially and the penetration depth into a polymer is of the order of some microns [20]. As the chemical reactions induced by the discharge activity on the surface progress, the changes in chemical composition and physical structure in the surface layer accessible by FTIR ATR are likely to approach an equilibrium state. As ageing continues, the chemical and physical structure of the polymer in the region below this surface layer will start to change. These changes in the bulk of the polymer will lead to continuing changes in the values of $\sigma_{0}$ and $\chi I$ as they are derived from bulk dielectric spectroscopy measurements while the FTIR ATR spectra remains unchanged leading to a saturation in the value of CI

The behavior of the results obtained when the samples were stressed at $\mathrm{AC} \% 30$ are more difficult to explain. The value of $\mathrm{CI}$ appears to be rising more rapidly as a function of $P_{C A}$ than is the case for samples stressed at $\mathrm{AC} \%$ 50. This behavior is also observed for $\chi I$ for PP aged at a temperature of $90^{\circ} \mathrm{C}$. When comparing the correlation between $\sigma_{0}$ and $\chi I$ the behavior in HDPE and the PP samples show a significant difference between the relationships observed at $\mathrm{AC} \% 30$ and $\mathrm{AC} \% 50$. A possible explanation comes from the approach used to calculate the apparent power delivery $P_{C A}$. In Equation (4), an assumption was made that the resistance of each individual discharge event $R_{D}$ could be replaced by a common effective resistance $R_{D E}$. However, there are considerable differences [10] in the range and averages of the recorded partial discharge voltages for the $\mathrm{AC} \%_{30}$ and 
$\mathrm{AC} \%{ }_{50}$ tests. The currents for the $\mathrm{AC} \%{ }_{30}$ tests are therefore significantly lower than those for the corresponding $\mathrm{AC} \% 50$ tests. From the behavior of channel resistance proposed in $[21,22]$, higher values of average channel resistance should occur for the discharges with lower currents. This would lead to higher values of the parameter $R_{D E}$ in Equation (5) for the $\mathrm{AC} \%{ }_{30}$ discharge activity, so the values of $P_{C A}$ at $\mathrm{AC} \%{ }_{30}$ may have been under-estimated. This would have the effect of moving the $\mathrm{AC} \%{ }_{30}$ data points in Figures 7 and 8 closer to the fit lines for the $\mathrm{AC} \% 50$ data. However an underestimate in the value of $P_{C A}$ does not explain the difference in the relationship between $\sigma_{0}$ and $\chi I$ observed at $\mathrm{AC} \% 30$. This suggests that while the energy of the discharges is still sufficient to cause the formation of polar groups, the energy is such that modification to the polymer structures and morphology occur at a much reduced rates.

\section{CONCLUSIONS}

Partial discharge based ageing experiments have been performed using combinations of $\mathrm{DC}$ and $\mathrm{AC}$ stressing on HDPE and PP polymer films. The degree of ageing of the polymers depends on both the magnitude of the $\mathrm{AC}$ component of the voltage and on its frequency. The effects of ageing on the polymer have been quantified using 3 parameters: the DC conductivity $\sigma_{0}$; a proposed Susceptibility Index $\chi I$, both derived from dielectric spectroscopy data and the Carbonyl Index derived from FTIR-ATR spectroscopy data. For the ageing conditions using a 50\% voltage ratio there are strong correlations between $\sigma_{0}$ and $\chi I$. Correlations between these parameters may also exist at the $30 \%$ voltage ratio but the proportionality between the parameters is different.

When comparing the Carbonyl Index with the parameters extracted from the dielectric spectroscopy data a clear saturation behavior was observed for CI at higher degrees of ageing. This reflects the fact that FTIR-ATR detects changes within a few microns of the polymer surface unlike dielectric spectroscopy, which detects changes in the bulk of the sample. The results indicate that as the sample ages the damage extends into the bulk to the polymer.

A simple method of estimating the apparent power delivered to the partial discharges, $\mathrm{P}_{\mathrm{CA}}$, has been presented. Despite the assumptions made, linear correlations exist between the derived values of $\mathrm{P}_{\mathrm{CA}}$ and the parameters $\sigma_{0}$ and $\chi I$ for the $50 \%$ stressing condition. The approach appears to be appropriate as long as the mean and distribution of the partial discharge magnitudes are similar.

The ageing conditions reported in this paper were extreme, in service conditions, the voltage ratio is unlikely to exceed $10 \%$ and no significant ageing was observed at this voltage during the one hour tests performed. Longer tests at lower values of voltage ratio are required to determine the life surface as a function of voltage ratio. It will also be necessary to determine the relationship of the derived parameters $\sigma_{0}$ and $\chi I$ with a parameter such as breakdown strength directly related to the residual life of the materials.

\section{REFERENCES}

[1] L. Xu, L. Yao and C. Sasse, "Grid integration of large DFIG-based wind farms using VSC transmission," IEEE Trans. Power Syst., vol. 22, no. 3, pp. 976-984, Aug. 2007.

[2] P. Bresesti, W. L. Kling, R. L. Hendriks and R. Vailati, "HVDC connection of offshore wind farms to the transmission system," IEEE Trans. Energy Convers., vol. 22, no. 1 pp. 37-43, Mar. 2007.

[3] C. Guo, Y. Zhang, A. M. Gole and C. Zhao, "Analysis of dual-infeed HVDC with LCC-HVDC and VSC-HVDC," IEEE Trans. on Power Del., vol. 27, no. 3 pp. 1529-1537, Jul. 2012.

[4] C. H. Chien and R. W. G. Bucknall, "Analysis of harmonics in subsea power transmission cables used in VSC-HVDC transmission systems operating under steady-state conditions," IEEE Trans. Power Del., vol. 22, no 4; pp. 2489-2497, Oct. 2007.

[5] H. H. Sæternes, J. Aakervik and S. Hvidsten, "Water treeing in XLPE insulation at a combined DC and high frequency AC Stress," IEEE Int.Conf. Electr. Insul. (ICEI), pp. 494-498, 2013.

[6] F. Mauseth, M. Amundsen and H. Faremo, "Water tree growth of wet XLPE cables stressed with DC and high frequency AC voltage superimposed," IEEE Int. Conf. Electr. Insul. (ICEI), pp. 266-269, 2012.

[7] W. Zhao, W. H. Siew, M. J. Given, E. Corr, Q. Li and J. He “ Assessment of HDPE aged under DC voltage combined with AC harmonic stresses of various Frequencies," IEEE Trans. on Dielectr. Electr. Insul., vol. 24, no.2 pp. 1189-1196, Apr. 2017.

[8] W. Vahlstrom, "Strategies for field testing medium voltage cables," IEEE Electr. Insul. Mag., vol. 25, no. 5, pp. 7-17, Sept. 2009.

[9] L. Barbeş , C. Rădulescu , C. Stihi, "ATR-FTIR spectrometry characterisation of polymeric materials", Romanian Rep. Phys., Vol. 66, No. 3, P. 765-777, 2014

[10] W. Zhao "Partial discharge ageing of polymer insulation under combined AC and DC stress at elevated temperatures,", Ph.D. Thesis, University of Strathclyde, Glasgow, UK, 2017.

[11] E. Chiellini, A. Corti, S. d'Antone and R. Baciu, "Oxo-biodegradable carbon backbone polymers-Oxidative degradation of polyethylene under accelerated test conditions," J. Polym. Degrad. Stab., vol.91, no. 11 pp. 2739-2747, Nov. 2006.

[12] E. Strömberg, S. Karlsson, "The design of a test protocol to model the degradation of polyolefins during recycling and service life", J. App. Polym. Sci, vol.112, issue. 3, pp.1835-1844, 2009.

[13] A. K. Jonscher, "A new understanding of the dielectric relaxation of solids,” J. Mat. Sci., vol.16, no.8, pp.2037-2060, 1981.

[14] T. Zhou, G. Chen, R Liao, and Z. Xu "Charge trapping and detrapping in polymeric materials: Trapping parameters," J. App. Phys., vol. 110, no. 4, pp. 043724, Aug. 2011.

[15] V.A. Goldade, L.S. Pinchuk, A.G. Kravtsovand and S.V. Zotov "TSDstudy of Polyethylene photochemical degradation," Proc. 2004 Int. Conf. on Solid Dielectr. (ICSD), France, pp. 347-350, 2004.

[16] G. Mazzanti ; G.C. Montanari ; J.M. Alison, "A space-charge based method for the estimation of apparent mobility and trap depth as markers for insulation degradation -theoretical basis and experimental validation," IEEE Trans. on Dielectr, and Electr. Insul., vol. 10, no. 2 pp. 187-197, Apr. 2003.

[17] L.A. Dissado and J.C. Fothergill, "Electrical degradation and breakdown in polymers,". Peter Peregrinus-IEE. 1992

[18] P.H. Morshuis, "Degradation of solid dielectrics due to internal partial discharge: some thoughts on progress made and where to go now," IEEE Trans. on Dielectr. and Electr. Insul. vol. 12, no. 5 pp. 905 - 913: Oct. 2005

[19] A. Tidjani, "Comparison of formation of oxidation products during photo-oxidation of linear low density polyethylene under different natural and accelerated weathering conditions,", J. Polym. Degrad. Stab. vol. 68, no. 3pp 465-469, May 2000.

[20] J. D. Schuttlefield and V. H. Grassian "ATR-FTIR Spectroscopy in the Undergraduate Chemistry Laboratory. Part I: Fundamentals and Examples," J. Chem. Educ., vol. 85, no. 2, p 279-288, Feb. 2008R

[21] Rompe and W. Weizel, "Uber das Toeplershe Funkengesetz," Z. Physicz, vol. 122, pp. 636-639 1944

[22] I. Kang, O. Fujiwara, J. Wang, "Analytical approach to the spark resistance formula caused by electrostatic discharge," Electron. Lett., vol. 33, no. 14, pp. 1203-1204, Jul. 1997. 